\title{
IS014001: 2015 Self-Assessment Tool for SME/SMI
}

\author{
Fouzi Belmir, Imane Zahri, Nouzha Jebbour \\ Catalysis, Materials and Environment Laboratory, High School of Technology, University Sidi Mohammed Ben Abdellah, Fes, Morocco
}

\section{Email address:}

fouzi.belmir@usmba.ac.ma (F. Belmir)

\section{To cite this article:}

Fouzi Belmir, Imane Zahri, Nouzha Jebbour. ISO14001: 2015 Self-Assessment Tool for SME/SMI. International Journal of Science, Technology and Society. Vol. 9, No. 1, 2021, pp. 21-31. doi: 10.11648/j.ijsts.20211001.13

Received: December 5, 2020; Accepted: December 23, 2020; Published: March 12, 2021

\begin{abstract}
In order to improve their overall performance, the establishment of an environmental management system has become a must for businesses. These systems also meet the requirements of external parties interested in environmental management. By modifying their management practices to adapt to a complex economic and competitive environment, companies have evolved this environmental management standard since its creation in 1996. The latest version, published in October 2015, adopts the philosophy of previous versions on the predominant place of the customer and integrates new concepts. The issue addressed in this article is to provide assistance to companies wishing to understand the standard and evaluate their Environmental Management System in relation to the specifications of the standard. In order to assist SMEs (small and medium-sized enterprise) in the deployment of ISO14001 version 2015, and after a detail In order to improve their overall performance, the establishment of an environmental management system has become a must for businesses. This is an important opportunity to reorganize their management of the environment, both internally and vis-à-vis external actors. This reorganization is generally motivated by an evolution of the technical strategy for environmental protection, towards integrated management and towards continuous improvement. These systems also meet the requirements of external parties interested in environmental management. By modifying their management practices to adapt to a complex economic and competitive environment, companies have evolved this environmental management standard since its creation in 1996 which has gained decisive international notoriety and importance. The latest version, published in October 2015, adopts the philosophy of previous versions on the predominant place of the customer and integrates new concepts while contributing to improved transparency, increased performance and new opportunities. The issue addressed in this article is to provide assistance to companies wishing to understand the principle of the standard and evaluate their Environmental Management System in relation to the specifications of the standard. In order to assist SMEs in the deployment of ISO14001 version 2015, and after a detailed analysis of the main requirements of this standard, A self-diagnostic tool is developed. It is aimed at companies of all sizes and all sectors of activity, to accompany them in their implementation of ISO14001, prepare them or facilitate their first certification or transition to the 2015 version. And after a detailed analysis of the main requirements of this standard, A selfdiagnostic tool is developed. It is aimed at companies of all sizes and all sectors of activity, to accompany them in their implementation of the ISO14001, prepare them or facilitate their first certification or transition to the 2015 version.
\end{abstract}

Keywords: Environmental Management System (EMS), ISO14001: 2015, Self-diagnosis, Continuous Improvement, Sustainable Development (SD), SME/SMI

\section{Introduction to Environmental Management and SD}

The implementation of an environmental management system becomes a necessity for companies of all kinds, first to improve their overall performance and then to meet the demands of external parties interested in their environmental management.

The purpose of this article is to describe the functioning of the self-diagnostic tool of ISO14001, after having recalled the specificities of the environmental dimension and the norm. The strategy of any company, whatever its sector of activity, is now in the perspective of sustainable development; the environment, which is one of the three pillars, must therefore be integrated. 
Note: Sustainable development is based on three pillars: the economic pillar, the social or societal pillar and the environmental pillar.

The accession of companies to the ISO14001 environmental management system (EMS) certification is one of the most significant phenomena among all voluntary initiatives by companies in the field of environmental protection and Sustainable development. Between 1996 and the year of publication, ISO14001 was used as a reference for 6,090 certifications in France, 96,196 in Europe and 203,098 in the world. [1, 13]

ISO14001 is the standard that defines the criteria for an environmental management system. Its objective is to encourage organizations to continuously improve their practices in this field. Any type of organization, regardless of its activities or sector, can use it and be certified. The standard provides assurance to management, staff and external stakeholders that their environmental impacts are being addressed and improved. The ISO14001 standard proposes to the economic actors, on a voluntary basis, to implement an environmental management system and to obtain a certification of company that they can use in their external communication. The concept of an environmental management system resumes quality assurance rules and transposes them into the industrial environment (reduction of energy and raw material consumption, waste management and rejections, etc.). The ISO14001 standard does not address how an organization eliminates or reduces its hazardous waste, or how it builds its processes for greater environmental effectiveness. It deals with the implementation, by a body, with the structure of management which will guarantee, among others, that the programs for the reduction of the hazardous or chemical waste will be applied, that the processes will be documented, that the environmental targets will be established and reached, etc. The purpose of an EMS is to provide assistance to companies allowing them to better manage their environmental impacts and improve their results. It is based on the continuous improvement of the overall performance; the purpose being to settle of new objectives when the first ones are reached, etc.

The ISO14001 standard does not define precise objectives, or technologies, or even a particular form of organization. Through general recommendations, it invites companies to rethink and formalize their organization while respecting some rules concerning the following points: management commitment, planning of improvements and management of activities, organization of corrective and preventive actions, training of staff in the field of the environment.

An accredited external auditor verifies the organization's compliance with the requirements of the standard. The company is certified if the audit report is conclusive. The steps for setting up an EMS are designed according to the improvement model known as the Deming wheel, namely: plan, do, check, act. In this context, "planning" refers to the stage of the definition of environmental policy and the planning of objectives, "doing" to that of implementation, "checking" to that of control and "reacting" to that of the executive review.

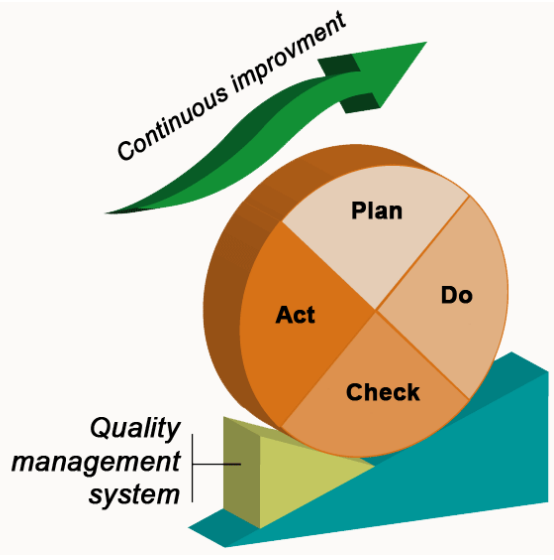

Figure 1. The Deming wheel [2].

Below is a table that describes the ISO14001 standard in detail;

Table 1. Description of ISO14001 [3].

\begin{tabular}{ll}
\hline Status & $\begin{array}{l}\text { Standard resulting from an international consensus formed by a certifiable normative part (mandatory) and by an } \\
\text { informative part: appendices }\end{array}$ \\
$\begin{array}{l}\text { Geographic coverage } \\
\text { Objective }\end{array}$ & $\begin{array}{l}\text { International } \\
\text { The improvement of the Environmental management system and not explicitly the environmental performances. } \\
\text { The standard does not require compulsory communication towards the public. }\end{array}$ \\
Result & Any economic activities (transport, services, administrations,...) The certification can be based on the whole organization, \\
Implication of the authority & the part of this one or on a combination of several units... \\
Audit & Certification by a certification body (accredited third). \\
& The authority is not involved in the procedure of certification. \\
& Require an audit of the EMS. The environmental performances of the company -are not explicitly auditedll.
\end{tabular}

\section{History and Evolution of the Standards ISO14001}

All the standards of the management system ISO are the object of a regular revision according to the rules which:
The following objectives to preserve its relevance on the current market and in the future:

1) Allow the integration with other management systems

2) Get an approach integrated into the organizational management

3) Reflecting the increasingly complex environments in which organizations operate. 
4) Improve an organization's ability to address environmental impacts.

Born in 1996 of the report when the world trade can develop only by fighting against the damages of the planet, the standard ISO14001 has for objective to incite organizations to set up a management system to improve durably their environmental practices $[13,14]$.

Its practical and common-sense approach is particularly appreciated by its users, who quickly measure their effects:

optimized management of the environment, better productivity of employees, significant impact on the economic performance of the organization...

The first standard on environmental management, ISO14001 is particularly appreciated for its operational aspect. Adopted by more than 250,000 certified users in 155 countries, the ISO14001 standard evolves in 2015 to take into account the evolution of the markets and the expectations of the company. Improving environmental performance, integrating external stakeholders, prioritizing risks, defining issues... the new version of the standard confirms its fundamentals but explores new avenues. [1] The first version of ISO14001 was published in September

1996. The standard was subsequently revised in December 2004, which made some minor changes to make it clearer and more compatible with ISO 9000 quality standards. [4] In October 2015 appears the latest revision of the standard, which reinforces the role of management, introduces life cycle analysis in environmental aspects. This requires concrete results from the organizations, unlike the latest versions.

ISO14001: 2015 has passed through all stages, the publication date is in September 2015 (ISO 2015a

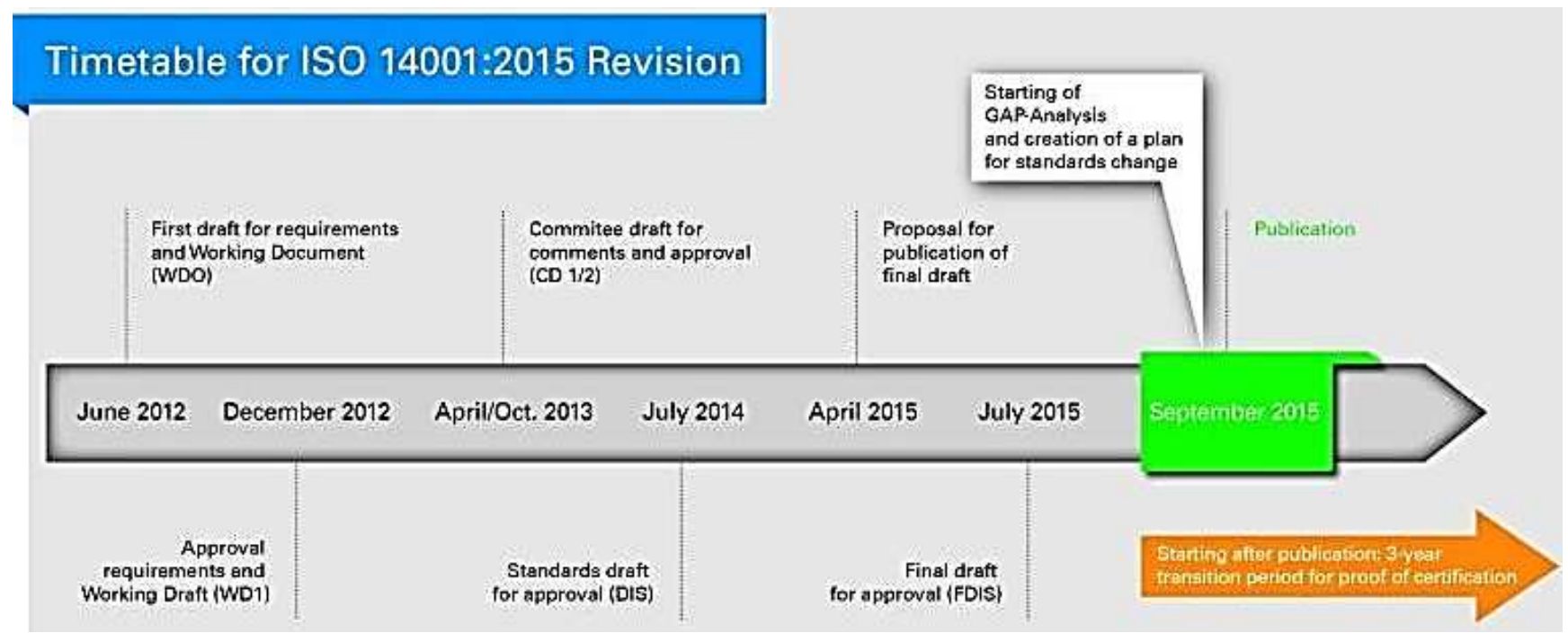

Figure 2. Timetable for the ISO14001: 2015 review process [10].

The draft ISO14001: 2015 is exploring new avenues to help organizations develop sustainable business practices that will, hopefully, improve their SD practices along a performance line.

\section{Analysis of the Requirements of the ISO14001: 2015 and Main Changes}

The main changes identified in the draft ISO14001: 2015 concerns the emphasis on risk management and improvement of environmental performance rather than on the management system itself.

In fact, the changes will address:

1) The increased importance of environmental management in the organization's strategic planning processes;

2) The importance of management's role and commitment. The new standard invites managers to become more involved in order to meet the challenges of the organization;

3) The adoption of a lifecycle perspective to address environmental aspects;

4) The introduction of a communication strategy to allow more transparency and credibility to the interested parties (AFNOR 2015).

ISO14001: 2015 is based on Annex SL, the new highlevel structure (SHN) which provides a common framework for all management systems.

This makes it possible to remain coherent, to coordinate different management system standards, to propose sub clauses that correspond to the high level structure and to apply a common language between all the standards.

With the new standard in place, organizations will be able to more easily integrate their environmental management system with the main business processes and promote the involvement of management.

Based on Annex SL, Figure 3 shows how the clauses of the new high-level structure could also be applied to the Plan, Develop, Control, Adjust cycle. The PDCA cycle can be applied to all processes and to the environmental management system as a whole. 
Table 2. The main changes of ISO14001.

\begin{tabular}{|c|c|}
\hline New / Updated concept & Commentaries \\
\hline Context of the organization & $\begin{array}{l}\text { The organization will have a better understanding of the important points that may affect, both positively and } \\
\text { negatively, how it manages its environmental responsibilities }\end{array}$ \\
\hline Questions & $\begin{array}{l}\text { Questions can be internal or external, positive or negative and include conditions that affect or are affected by the } \\
\text { organization }\end{array}$ \\
\hline Interested Parties & $\begin{array}{l}\text { Much more detail of the consideration of their needs and expectations before deciding whether to adopt one of them as } \\
\text { compliance obligations }\end{array}$ \\
\hline Leadership & Specific Requirements for Management and Leaders in the EMS \\
\hline Compliance Obligations & Replaces "Legal Requirements" and other requirements to which the organization subscribes \\
\hline $\begin{array}{l}\text { Environmental objectives and } \\
\text { planning process }\end{array}$ & $\begin{array}{l}\text { Higher level of detail regarding environmental objectives, which must now reflect planning to achieve them (see risk } \\
\text { associated with threats and opportunities below) and include the identification of appropriate indicators }\end{array}$ \\
\hline Communication & There are explicit and more detailed requirements for internal and external communications \\
\hline Operational Planning and Control & $\begin{array}{l}\text { Generally more detailed requirements, with consideration of the supply, operational of the design and the } \\
\text { communication of environmental "corresponding requirements in a prospect of life cycle" }\end{array}$ \\
\hline Conformity assessment & More detailed requirements for maintaining knowledge and understanding the status of compliance levels. \\
\hline Non-compliance and action & More detailed assessment of non- conformities and corrective actions required \\
\hline Management review & More detailed requirements related to the inputs and outputs of the review \\
\hline
\end{tabular}

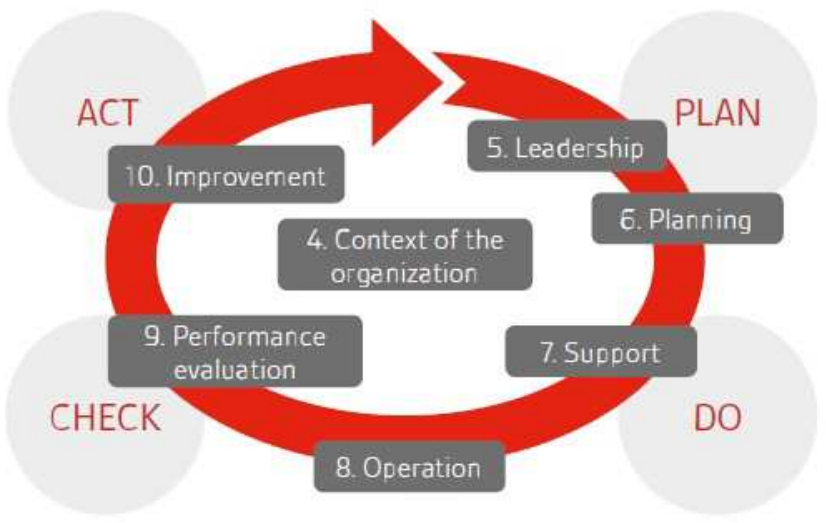

Figure 3. The PDCA cycle [5, 15].

The changes made to the ISO14001 standard can be described as follows: The changes made to the ISO14001 standard can be described as follows:

The first notable change is Clause 4: The Context of the Organization. It is an entirely new clause that allows for a more sophisticated and strategic understanding of all the factors affecting how organizations manage their environmental responsibilities.

Clause 5: Leadership has been redesigned to ensure greater involvement, responsiveness, active support and feedback from senior management. "Changes to this clause will require a real change in how Certification Bodies will audit the standard," according to Nigel.

The concept of planning the preventive actions will now be covered in Clause 6: Planning. The Committee considered that this section was more appropriate than the "action part" in the previous standard. This clause will focus on enhancing awareness and skills.

Although the requirements of Clause 7: Help have not changed, they will be more normative to promote coherence within the organization. The clause distinguishes between internal and external communication and requires more detail during external reporting.

Clause 8: Operations, now focuses more on the concept of "value chain", which has an impact on the environmental management system. It also looks at how organizations control change and outsource specific processes.

Clause 9: Performance Assessment is a new clause bringing together several existing clauses from the previous version, including monitoring, measurement and management review. This will help companies to collect good records and prove that their environmental management system meets their business objectives.

A more structured approach has been suggested for Clause 10: Improvement. While retaining the principle of the current non-conformance and remedial clause, the new standard is more detailed in its consideration of non- compliance and consequent action required. [6].

\section{Approach to the Development of the Self-diagnosis Tool ISO14001}

The revision of ISO14001 encourages companies to implement changes in their environmental systems. Better understanding of the context, identifying stakeholders, anticipating risks and seizing opportunities to build a sustainable performance strategy are all challenges in 2015 and companies will have to face to obtain or renew their ISO14001 certification. Therefore, accompanying economic players in the deployment of ISO14001: 2015 requires developing solutions that, on the one hand, ensure that the requirements of the standard are understood by everyone involved and on the other hand.

Management system.

The ISO14001: 2015 standard, as such, requires clarification and illustration among users so that they can exploit it in the best possible conditions. First, it is a question 
of elaborating a simple document to read allowing a global visualization of the requirements of the norm and their understanding in a playful way. In addition, organizations will need to assess their level of compliance compared with the standard, identify gaps between the initial situation and the target, but also monitor the progress of the implementation of the action plans. In this case, making all the requirements of the standard visible with different levels of compliance allows users to identify priority points.

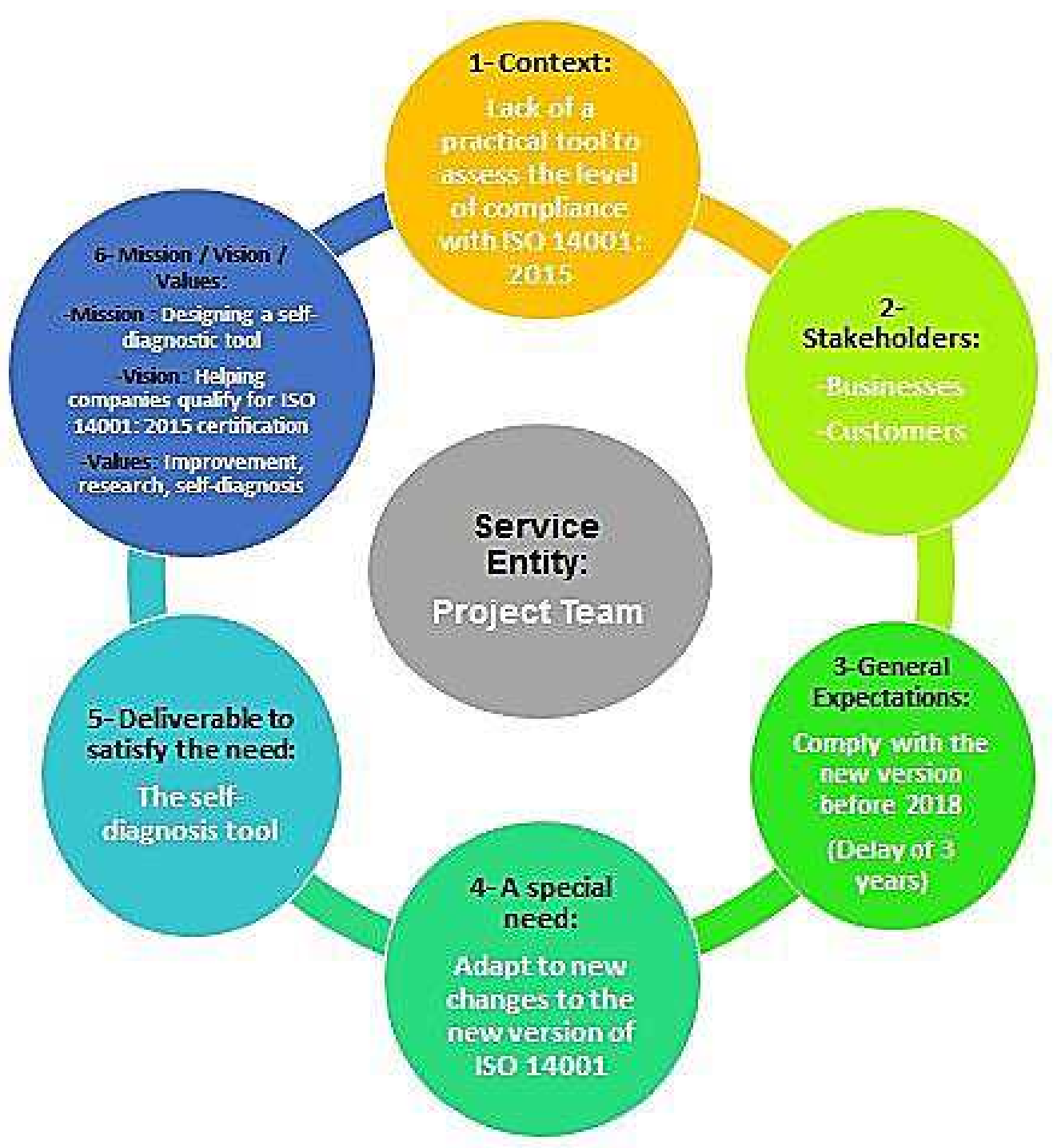

Figure 4. Problems and solutions targeted [source authors].

The development of a self-diagnostic tool for ISO14001: 2015 is the most appropriate way to meet the above requirements make it possible to establish an initial diagnosis and then a regular evaluation of the environmental management system with a view to progress. This support, aimed at any organization, is intended to revitalize their quality approach in order to implement a management system that is certifiable. [7]

Deployment support solutions must satisfy all users regardless of their level or knowledge of the Strategic planning integrating the input and output of the problem has been put in place in order to have a global vision of the project.

A tool based on the Final Draft version of ISO14001: 2015, in Excel format, was used to develop the self-diagnosis tool.

This tool offers a greater number of advantages in terms of development and functionality. In addition, the use of Excel as a development support that is professional software, known and used in most businesses is a sure asset for broadcasting.

Priority is given to the easy understanding of requirements, intuitiveness, ergonomics and readability of the results.

The tool should be short and simple. It must be intuitive, self-supporting, functional and fluid. The aim is to present an effective solution to evaluate the conformity of the EMS with the requirements of the standard and to identify the priorities for improvement.

It will be structured and will contain:

1) A manual 
2) The criteria structured according to the last 7 articles of the standard (4 to 10)

3) Clear, concise and understandable requirements

4) An evaluation scale

5) Overall results by article

6) A guide explaining the purpose of each article in the standard

The evaluation of the tool will be based on its functioning i.e. utility, ease of use and ergonomics [8].

\section{Presentation of the Tool}

The purpose of the self-diagnosis tool is to assess the level of compliance with the requirements of ISO14001 version 2015 , to visualize the performance of the environmental management system through radar graphs and to identify the areas of progress in order to initiate a process of continuous improvement.

The diagnosis is done autonomously with a rhythm defined by the users. It can also be carried out in groups, which encourages participatory and collaborative approaches. This tool in Excel ${ }^{\circledR}$ format contains a requirements form following the ISO14001 model. [9, 11]

The self-diagnosis tool allows: [12]

1) Make an inventory of the EMS in relation to the standard,

2) Develop action plans based on initial diagnosis,

3) Communicate results internally,

4) Manage and monitor the implementation of defined actions (Who, When, Where?). [13]

For this, it is structured into 6 main tabs: User's Manual, Requirements, Diagnostic Notes, Overall Results, Results by Article, Tips. [Source authors]

\subsection{User's Manual Tab}

This first tab explains the instructions for use, presenting the tool and its parts. It serves to understand the objectives of the tool and introduces the component elements of each tab.

It contains a dynamic summary that shows shortcuts to the various tabs of the tool and the results of each article.

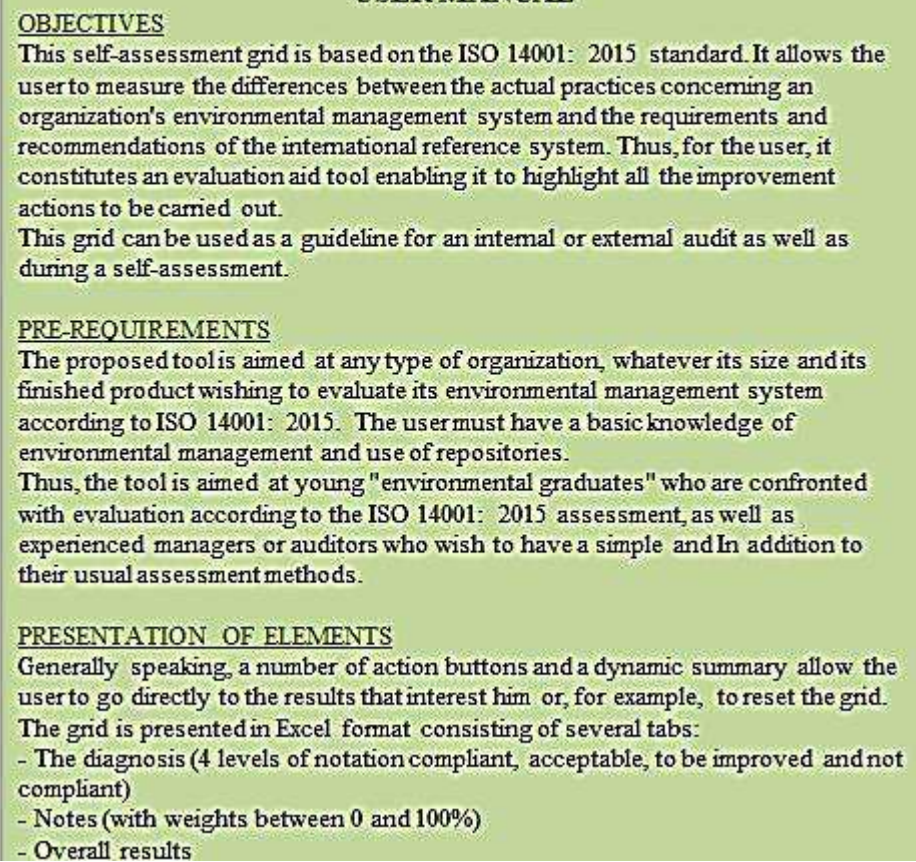

This self-assessment grid is based on the ISO 14001: 2015 standard. It allows the user to measure the differences between the actual practices concerning an organization's environmental management system and the requirements and recommendations of the intemational reference system. Thus, for the user, it constitutes an evaluation aid tool enabling it to highlight all the improvement actions to be carried out.

This grid can be used as a guideline for an intemal or extemal audit as well as during a self-assessment.

\section{PRE-REQUIREMENTS}

The proposed toolis aimed at any type of organization, whatever its size andits finished product wishing to evaluate its environmental management system

according to ISO 14001: 2015. The user must have a basic knowledge of environmental management and use of repositories.

Thus, the tool is aimed at young "environmental graduates" who are confronted with evaluation according to the ISO 14001: 2015 assessment, as well as experienced managers or auditors who wish to have a simple and In addition to their usual assessment methods.

\section{PRESENTATION OF ELEMENTS}

Generally speaking, a number of action buttons and a dynamic summary allow the user to go directly to the results that interest him or, for example, to reset the grid. The grid is presented in Excel format consisting of several tabs:

The diagnosis ( 4 levels of notation compliant, acceptable, to be improved and not compliant)

Notes (with weights between 0 and $100 \%$ )

Overall results

\section{USER MANUAL}

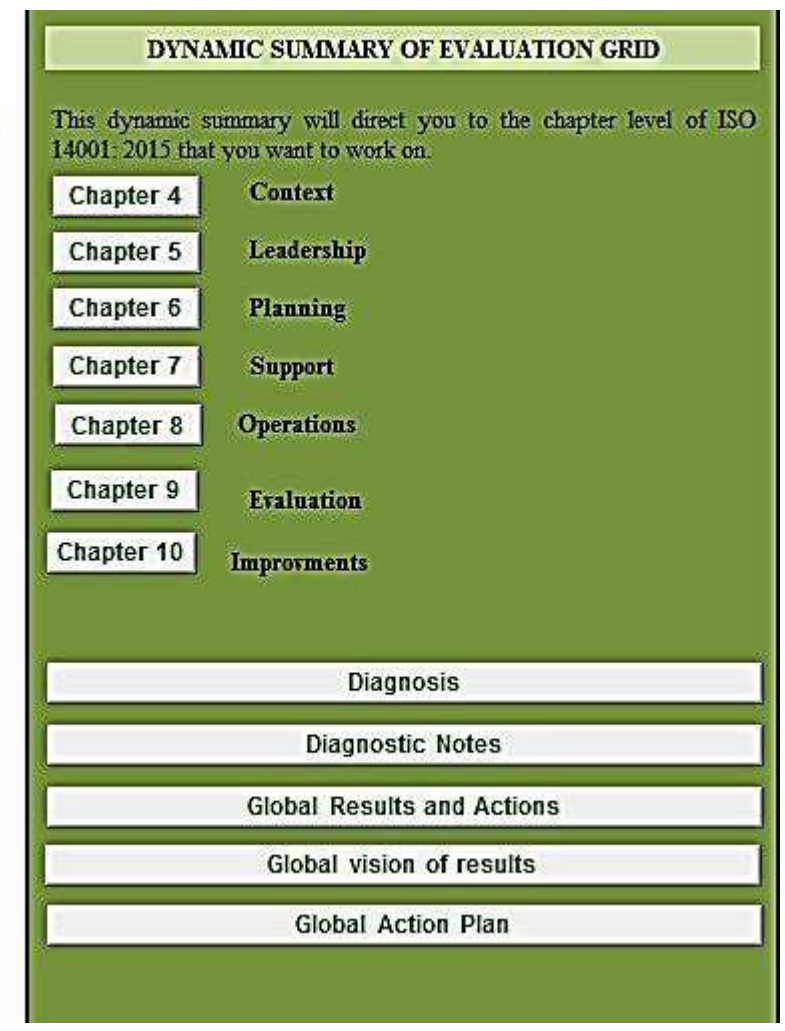

Figure 5. \{Requirements\} tab of the [author source]

\subsection{Requirements Tab}

The $\{$ Requirements $\}$ tab contains the requirements of the standard that are reformulated and classified into articles and sub-items.

The evaluation grid consists of the item to be assessed, the corresponding compliance rate.
The tool allows users to incorporate feedback as they see fit, as they are evaluated. The evaluation makes it possible to estimate the conformity of the EMS with the requirements of the reference system and is done according to 5 modalities:

Excluded (NA) / Not in conformity / to be improved/Acceptable/Compliant. 


\begin{tabular}{|c|c|c|c|c|c|c|}
\hline Reset the pack & \multicolumn{4}{|c|}{ EVALUATION GRID ISO 14001 version 2015} & & \\
\hline & \multicolumn{4}{|c|}{$\begin{array}{l}\text { ORGANZZATION EVALUATED: } \\
\text { EVALUATOR: } \\
\text { EVALUATION DATE: }\end{array}$} & & \\
\hline \multirow{2}{*}{ Back to Manual } & \multirow{2}{*}{$\begin{array}{l}\text { CHAPTERS OF THE } \\
\text { CORRESPONDING } \\
\text { STANDARD }\end{array}$} & \multirow{2}{*}{ CRITERIA } & \multicolumn{2}{|c|}{ To fill according to the level of satisfaction in the requirements } & \multirow{2}{*}{\multicolumn{2}{|c|}{ View global results }} \\
\hline & & & Evaluation & Observations & & \\
\hline $\begin{array}{l}\text { Visualize the results of } \\
\text { the Chapter } 4\end{array}$ & \multicolumn{6}{|c|}{ Chapter 4: Context of the Organization } \\
\hline \multirow{6}{*}{20,69} & \multirow{6}{*}{$\begin{array}{l}\text { 4.1 Understanding the } \\
\text { organization and its } \\
\text { particular contest }\end{array}$} & $\begin{array}{l}\text { Identify and understand your } \\
\text { organization's external context }\end{array}$ & Acceptable & $\nabla$ & 66 & \multirow{6}{*}{53,00} \\
\hline & & $\begin{array}{l}\text { Ijentify the external issues that are } \\
\text { relevant to your organization's } \\
\text { purpose }\end{array}$ & Acceptable & & 66 & \\
\hline & & $\begin{array}{l}\text { Identify the external conditions that } \\
\text { are relevant to your organization's } \\
\text { purpose }\end{array}$ & Improper & & 0 & \\
\hline & & $\begin{array}{l}\text { Identify and understand your } \\
\text { organization's internal contest }\end{array}$ & Compliant & & 100 & \\
\hline & & $\begin{array}{l}\text { Identify the internal issues that are } \\
\text { relevann to your organization's } \\
\text { purpose }\end{array}$ & Excluded (NA) & & $\mathrm{NA}$ & \\
\hline & & $\begin{array}{l}\text { Identify the internal conditions that } \\
\text { are relevant to your organization's } \\
\text { purpose }\end{array}$ & To improve & & 33 & \\
\hline
\end{tabular}

Figure 6. \{Requirements\} tab of the [author source].

The weighting is determined automatically according to the chosen level of compliance.

Table 3. Concordance Between Compliance Levels and Weightings [Source Authors].

\begin{tabular}{ll}
\hline Level of compliance & Weighting (\%) \\
\hline Excluded (NA) & NA \\
Improper & 0 \\
To improve & 33 \\
Acceptable & 66 \\
Compliant & 100 \\
\hline
\end{tabular}

\subsection{Diagnostic Notes Tab}

This tab represents the percentages (\%) of each item as well as the overall rating of the whole standard. The results are then schematically presented in the form of a histogram.

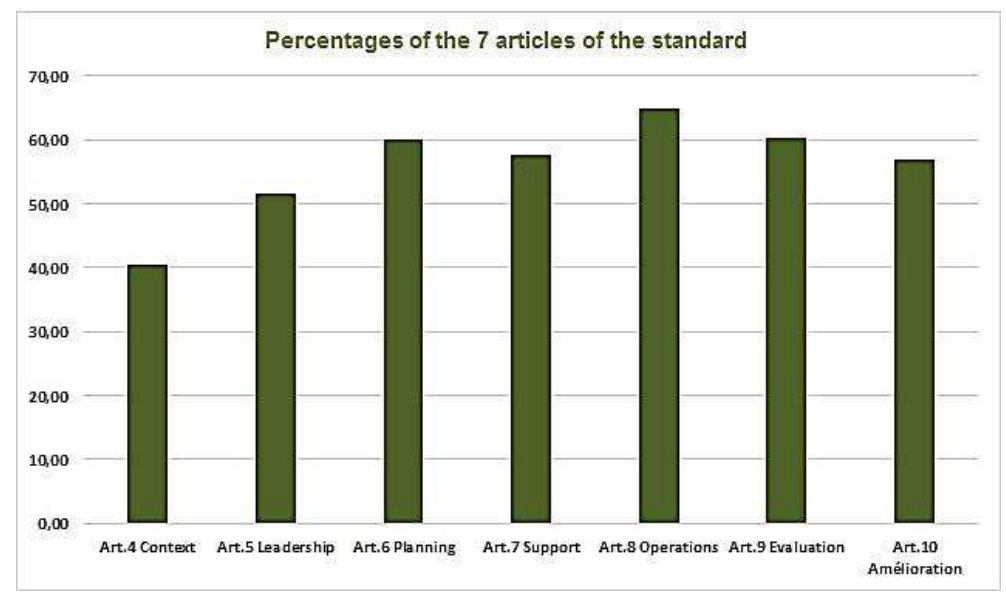

Figure 7. Histogram of article notes [source authors].

\subsection{Global Results and Actions Tab}

The tool allows, at the end of the evaluation, to synthesize the results by graphical representations. The \{Global Results and Actions $\}$ tab shows the global results in the form of a radar diagram, taking the conformity level of the articles to the requirements of the standard.

It therefore makes it possible to evaluate the efficiency of the EMS and to identify opportunities for improvement. The user can note his remarks and action plans by specifying the objectives to be reached, the persons responsible, as well as the scope of application and the deadlines. 


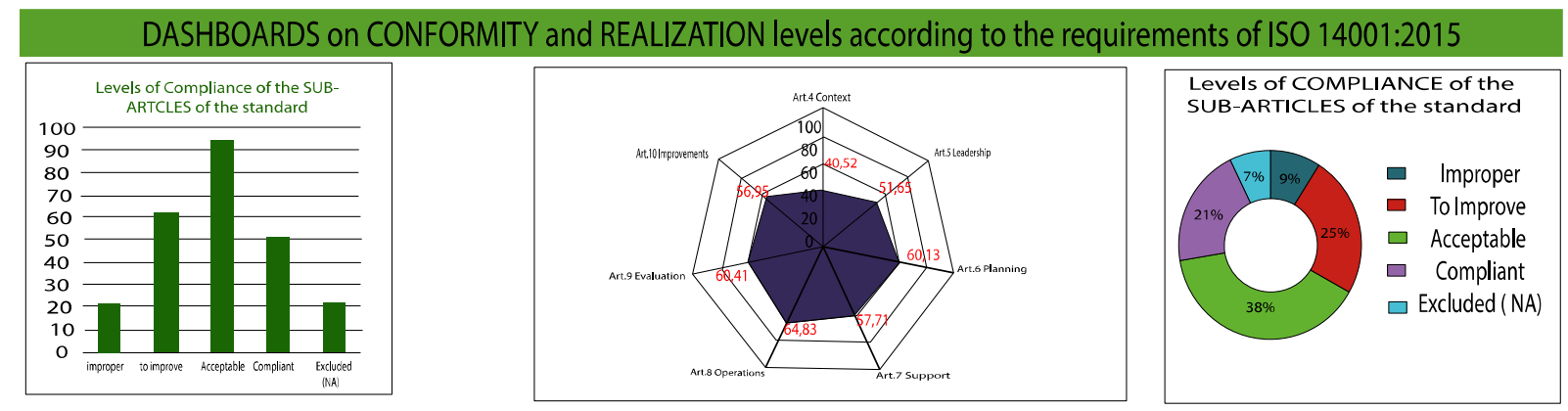

\section{BAL.ANCE SHEET, COMMIENTS AND IMPROVEMINT PLANS}
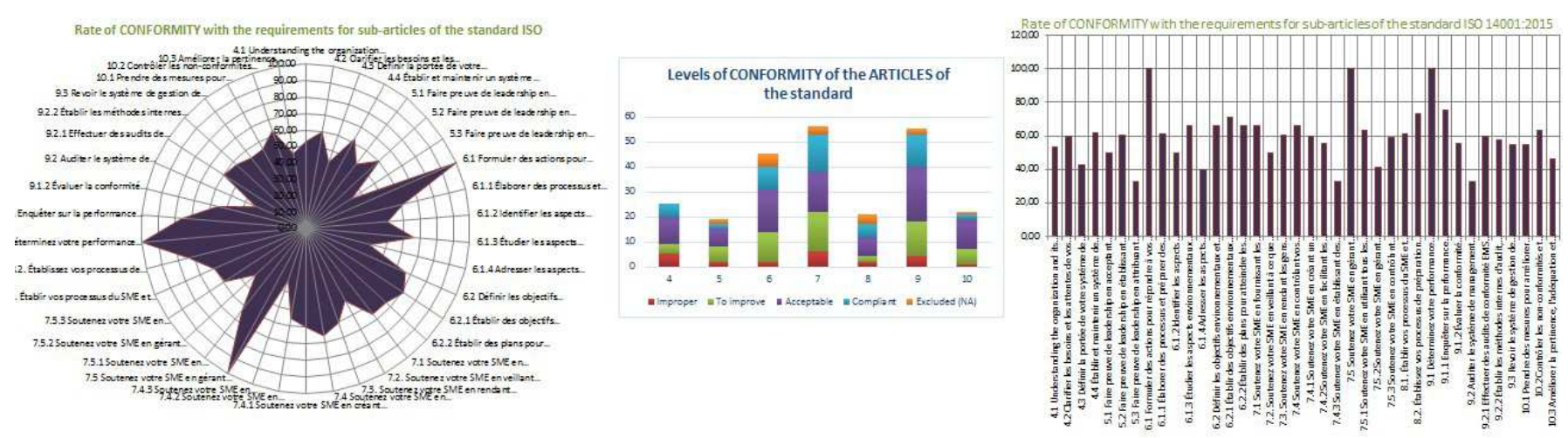

Figure 8. Global Results and Actions tab [author source].

\subsection{Results by Article Tab}

After an overall view of the results, it is possible to view the results of each article separately. The fact of having a fairly detailed representation, showing the positioning of each sub-article, gives better visibility on the sensitive points of the environmental management system.

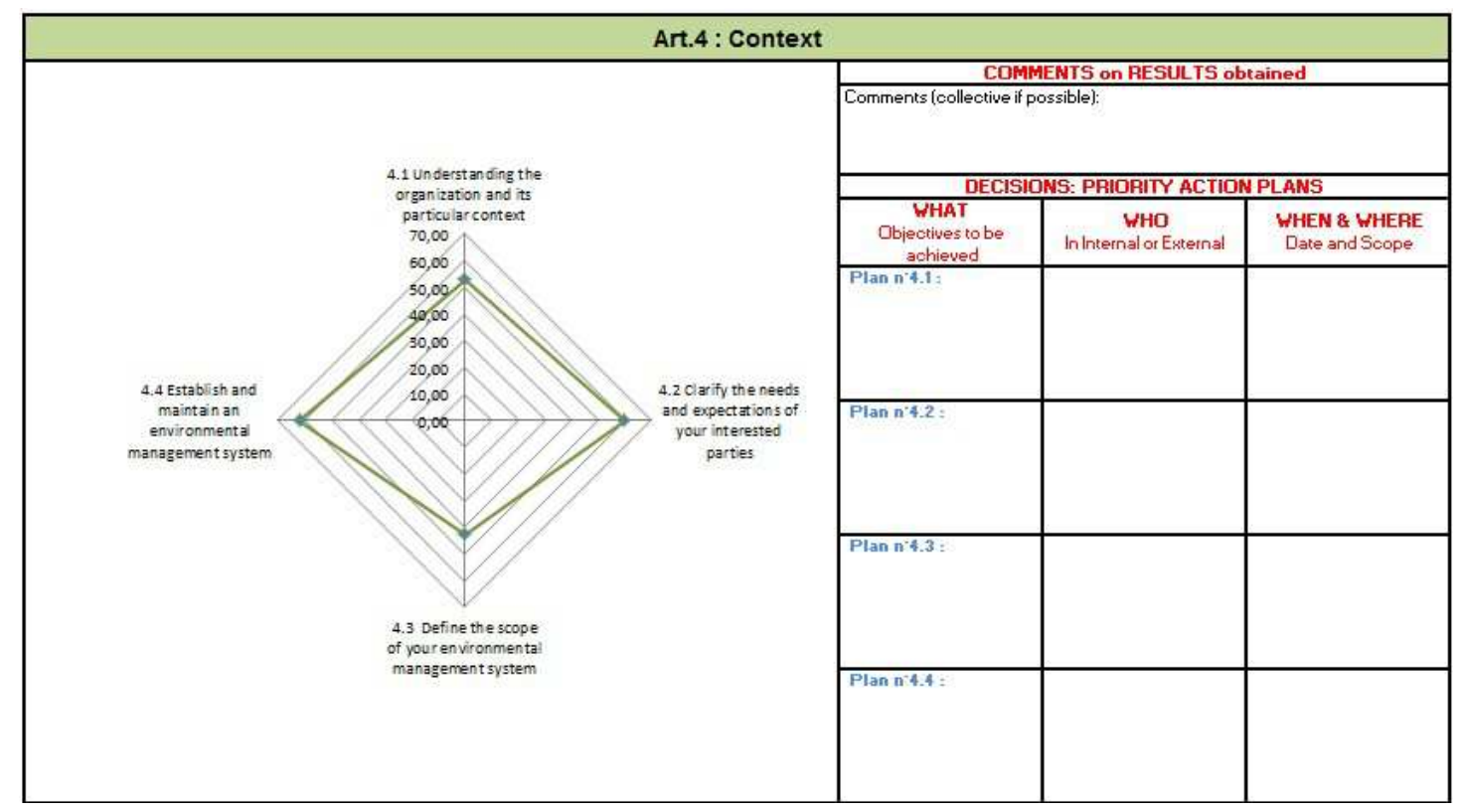

Figure 9. \{Results by article\} tab [author source].

\subsection{Tips Tab}

This section includes tips and suggestions adapted to each article of the standard. The items in this topic guide users by summarizing the content of each article. 


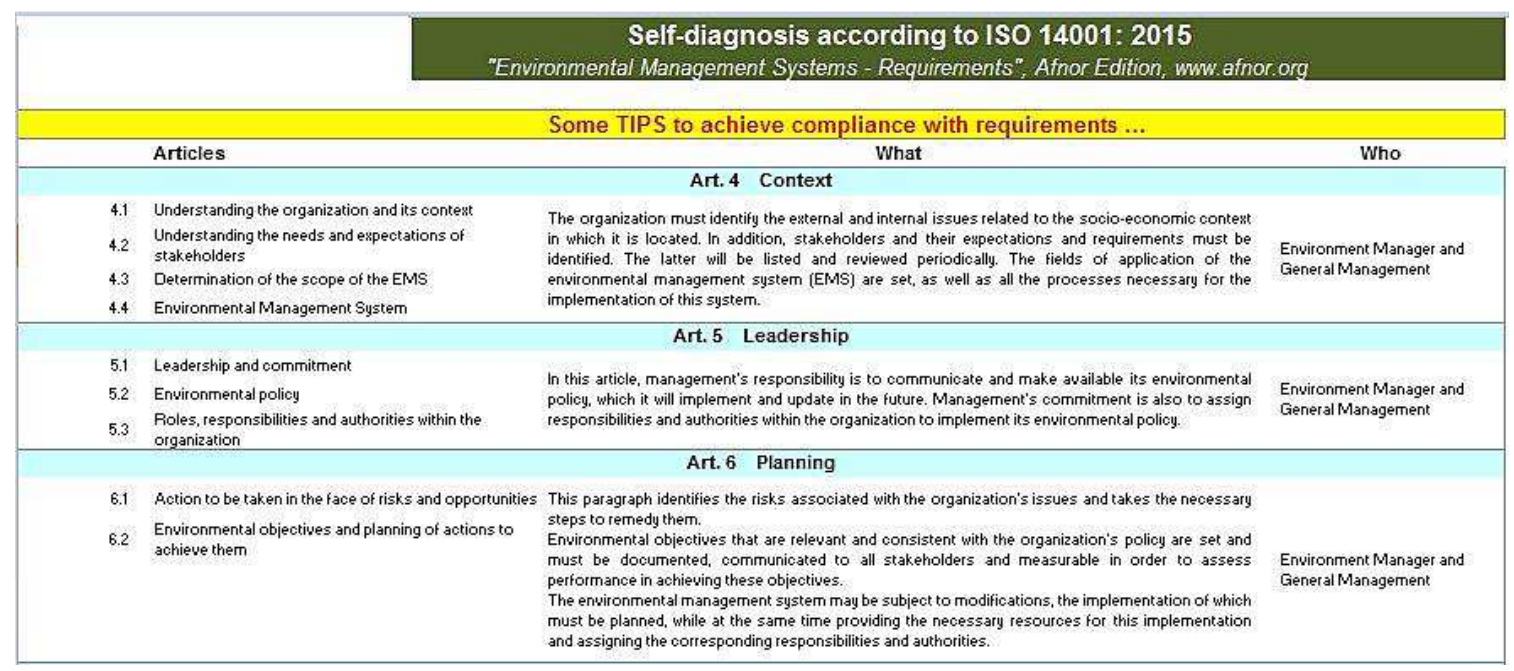

Figure 10. \{Tips\} tab [author source].

\section{Process for Using the Tool}

A flowchart of use of the tool has been developed in order to clarify its use. It details the procedure to be followed in order to obtain an optimal evaluation result.

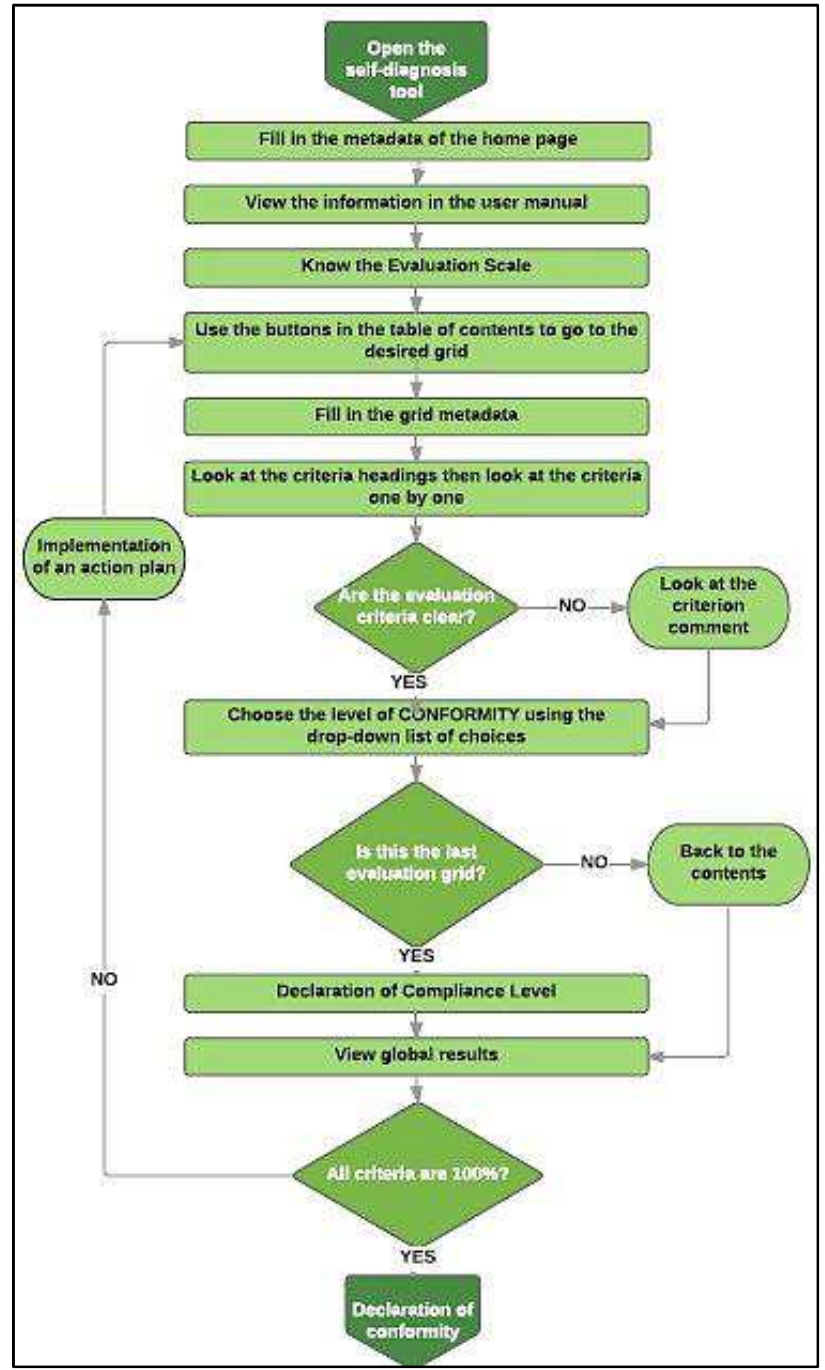

Figure 11. Diagram of use of the self-diagnosis tool [source authors]. 


\section{Evaluation of Self-Diagnostic Tool Performance}

In order to evaluate the self-diagnosis tool, a form has been put online. This form contains criteria to be evaluated by the users of the tool. They are invited to complete this form at the end of the evaluation. These feedbacks will improve the performance of the tool.

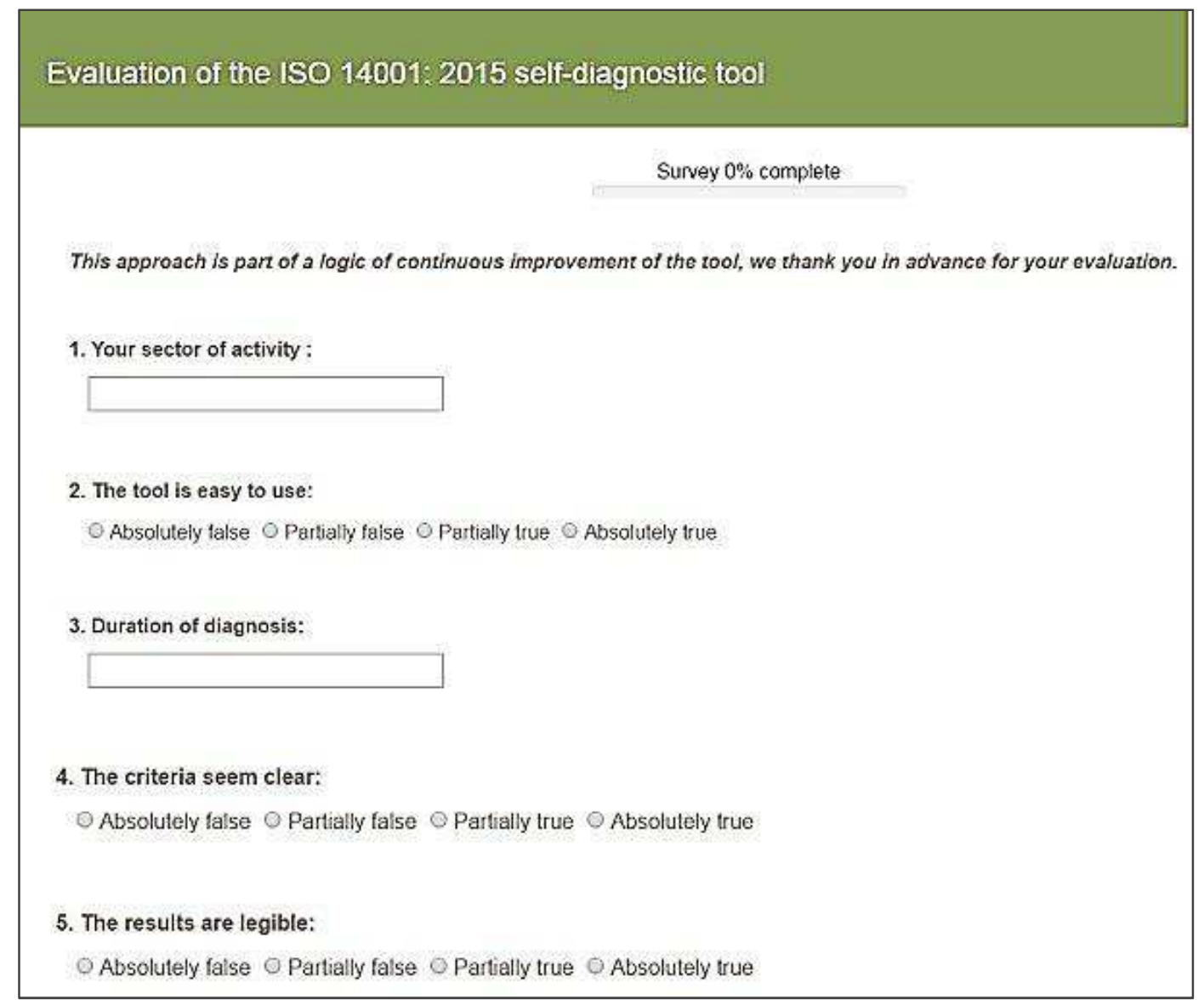

Figure 12. Evaluation Form for Self-Diagnosis Tool [source authors.

\section{Conclusion \& Perspectives}

This tool contains the principles, requirements and essentials of ISO14001: 2015 in order to meet all the requirements of this standard. Self-diagnosis is a quick solution to evaluate the EMS situation and to identify possible areas for improvement.

Using this tool, several mappings are obtained, including the results of each chapter of ISO14001 as well as mapping which summarizes more fully all the results of the various chapters. These results allow a direct visualization of the strengths and weaknesses of the conformations of the requirements of the environmental management system.

The self-diagnostic tool that is the deliverable of our project will have to be tested by environmental managers of some companies who will be used to improve their environmental management systems. Then, after validation of the tool by these users and after taking into account their remarks and suggestions, the grid can be widely disseminated to all interested parties. The possible improvements for our tool will be better clarified after feedback from our users.

\section{References}

[1] Afnor group, "Environment - ISO14001 Revision", http://www.afnor.org/profils/centre-d-interet/environnementrevision-iso-14001

[2] ISO, http://www.actuenvironnement.com/ae/dossiers/iso14000/iso_principe.php4

[3] E. Bauraing, J. Nicolas, M. von Frenckell, «Setting up an environmental management system», Arlon December 2000.

[4] Engineering techniques, "Environmental management: ISO 1400 standard", Saint-Denis October 2007.

[5] ISO, «Transition Guide: Moving from ISO14001: 2004 to ISO14001: 2015», www.iso.org

[6] ISO, «ISO14001 White paper ISO Revisions Context and update of the 2015 revision», www.iso.org.

[7] ISO, «The ISO Survey of Management System Standard Certifications - 2014». http://www.iso.org/iso/isosurvey. 
[8] Z. Barry, Z. Bensaid, I. Boukhris, S. Hamrit, F. Mnif et L. Soto, "Deployment assistance and self-diagnostic tool of the ISO 9001: 2015 standard", University of Technology of Compiègne, Master in Quality and Performance in Organizations (QPO), Thesis on Methodological Intelligence of the integration project, http://www.utc.fr/master-qualité, then "works" "Quality Management" ref n ${ }^{\circ}$ 338, Jan. 2016.

[9] I. Zahri. "Design of a self-diagnostic tool on the 2015 version of the ISO14001 standard". Higher school of arts and crafts, Industrial and production engineering. Memory of the training course at Minaret Consulting.

[10] Afnor group, http://fr.slideshare.net/GroupeAFNOR/afnorrevisionsiso900114001.
[11] M. Kadri, "Sustainable development, the company and ISO14001 certification", (C) L'Harmattan 2009.

[12] S. Mathieu, K. Naciri, «Self-diagnostic tools» AFNOR 2001 (2nd edition).

[13] F. Belmir, «QSE Management and sustainable development», $\mathrm{PhD}$ thesis, Sidi Mohammed Ben Abdellah University, Fez, Morocco, 2007.

[14] C. Boutin, C. Emard, G. Lalonde, «ISO14000- Environmental management system», Collection Formation Continue, Editions de l'Ecole Polytechnique de Montreal-1996.

[15] ISO14001: 2015 Standard, «Environmental management systems - Requirements and guidelines for its use». 